\title{
COMPARATIVE CASE STUDY BETWEEN THE CHARACTERISTICS THAT THE USE OF PASSIVE OR ACTIVE REINFORCEMENT IN RIBBED SLAB ATTRIBUTES TO THE CONSTRUCTION OF A GARAGE BUILDING
}

\author{
Daniele da Silva Duarte ${ }^{1}$, Euler André Barbosa de Alencar ${ }^{2}$, Iano Sá e Souza de Wanderley ${ }^{3}$
}

\footnotetext{
${ }^{1}$ Graduanda em Engenharia Civil pelo Centro Universitário do Norte (UNINORTE), Brasil, Avenida Igarapé de Manaus, 110 , Centro, Manaus.

${ }^{2}$ Pós Graduado em Gestão de Projetos em Engenharias e Arquitetura pelo Instituto de Pós Graduação e Graduação (IPOG), Brasil, Edifício The Office, Av. Mário Ipiranga, 315 - 904, Adrianópolis Manaus.

${ }^{3}$ Pós Graduado em Gestão de Obras Tecnologia e Qualidade da Construção pelo Instituto de Pós Graduação e Graduação (IPOG), Brasil, Edifício The Office, Av. Mário Ipiranga, 315 - 904, Adrianópolis, Manaus.
}

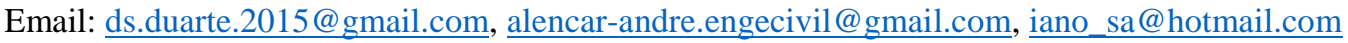

Received: March 21 th 2019

Accepted: April 29th 2019

Published: June 30th, 2019

Copyright @2016 by authors and Institute of Technology Galileo of Amazon (ITEGAM).

This work is licensed under the Creative Commons Attribution International License (CC BY 4.0). https://creativecommons.org/lice nses/by/4.0/

\begin{abstract}
The flexibility provided by buildings with larger spaces between pillars has increased its demand and popularity. For this reason, specific construction technics were developed to respond to this market demand. Some of the technics already developed are the ribbed slab and the prestressed concrete. In this context, this article aims to demonstrate how the choice between the use of reinforced concrete and prestressed concrete in ribbed slab influences the cost, the execution and the purpose of the construction of a garage building of $8,374 \mathrm{~m} 2$ of area, planned to respond to the needs of a judicial forum in Manaus. The data were collected based on the structural projects for each type of slab (with reinforced concrete and prestressed concrete). The article demonstrates through tables and graphs that the amount of structural items, as well as the amount of material used in the infrastructure and the cost of execution of the prestressed concrete slab are inferior when compared to the reinforced concrete slab, in addition the prestressed concrete slab exhibited more advantageous in terms of functionality and execution for this analyzed case.
\end{abstract}

Keywords: Ribbed slab, Reinforced concrete, Prestressed concrete.

\section{ESTUDO DE CASO COMPARATIVO ENTRE AS CARACTERÍSTICAS QUE O USO DE ARMADURA PASSIVA OU ATIVA EM LAJE NERVURADA ATRIBUI À CONSTRUÇÃO DE UM EDIFÍCIO GARAGEM}

\section{RESUMO}

A flexibilização que os vãos maiores trazem aos projetos faz crescer a preferência por edificações com essa característica, com isso surge a necessidade de utilizar-se de técnicas construtivas que atendam a esse mercado e algumas opções existentes são a laje nervurada e a protensão. Nesse contexto, este artigo visa demonstrar, como a escolha entre a utilização de armadura passiva ou ativa em laje nervura influencia nos custos, na execução e na finalidade da construção de um edifício garagem de $8.374 \mathrm{~m}^{2}$ de área, planejado para atender à demanda de um fórum de Manaus. O levantamento dos dados foi feito com base nos projetos estruturais para cada tipo de laje (armada e protendida). O artigo demonstra através de tabelas e gráficos que a quantidade de itens estruturais, assim como a quantidade de material utilizado na infraestrutura e o custo de execução da laje de concreto protendido são inferiores quando comparados à laje de concreto armado, além disso a laje de concreto protendido apresentou-se mais vantajosa quanto à funcionalidade e execução para este caso analisado.

Keywords: Laje nervurada, Concreto armado, Concreto protendido. 


\section{INTRODUÇÃO}

A variedade de técnicas, materiais e processos construtivos que envolvem o campo da construção civil, requer, da equipe envolvida em cada projeto, planejamento e conhecimento técnico relevante para combinar da melhor forma um projeto que atenda satisfatoriamente às necessidades dos clientes com o menor custo e qualidade pois de acordo com [1] a qualidade dos materiais empregados influenciará na solidez, na durabilidade, no custo e no acabamento da obra.

Além disso segundo [2] o custo da obra é um dos fatores sobre o qual as especificações técnicas e de acabamento incidem diretamente, por esse motivo, nos projetos de construção civil, atenção especial deve ser dada aos materiais e métodos construtivos escolhidos para o projeto pois são o que geralmente direcionam o orçamento da obra.

Conforme [3] dos itens que compõem uma edificação, por apresentar normalmente grande área de superfície, a parte da estrutura onde mais utiliza-se material é no pavimento, isso nos leva a concluir que a escolha da laje a ser utilizada norteará os valores que comporão o orçamento da obra como um todo.

Para os sistemas convencionais [3] explica que as ações verticais iniciam nas lajes que as transmitem às vigas, as quais transferem essas ações para os pilares que por fim as direcionam às fundações, portanto a escolha do tipo de laje utilizada refletirá no dimensionamento e quantidade de vigas que influenciará no dimensionamento e quantidade de pilares e por fim todo esse conjunto contribuirá para definir o tipo de fundação.

O objetivo deste trabalho é comparar o emprego da laje nervurada de concreto armado e laje nervurada protendida. A comparação entre os dois métodos construtivos busca mostrar as diferenças, vantagens e desvantagens na utilização de cada tipo de laje para o mesmo projeto. De acordo com [4] lajes nervuradas são moldadas na obra ou pré-moldadas, neste tipo de laje a zona de tração está localizada nas nervuras. Para este projeto o tipo de laje nervurada utilizada foi a moldada no local.

\section{MATERIAIS E MÉTODOS \\ II. 1 AREA DE ESTUDO OU OBJETO DE ESTUDO}

O estudo realizou um comparativo entre a utilização de laje nervurada de concreto armado e laje nervurada protendida na construção de um edifício garagem em determinado fórum de Manaus, o objetivo foi verificar a influência que cada tipo de laje atribui aos custos, à adequação da obra com a sua finalidade e demais vantagens e desvantagens observadas.

\section{2 COLETA DE DADOS}

A análise limitou-se a uma obra de edifício garagem composto de térreo mais 5 pavimentos, com $8.374,2 \mathrm{~m}^{2}$ de área construída para atender à demanda de um Fórum da capital Amazonense.

\section{3 ANÁLISE DOS DADOS}

A pesquisa foi realizada através de análise bibliográfica, a partir de documentos, manuais, literatura técnica e análise dos dois projetos estruturais.

Com o fim de comparar as características estruturais resultantes da escolha de cada tipo de laje foi levantado o quantitativo de todo o material necessário para compor a infraestrutura e superestrutura nos dois projetos.
A partir do levantamento do quantitativo foi possível comparar os orçamentos para verificar se houve alterações significativas no valor da obra.

Foi ainda verificado se ocorreram mudanças no que se refere à funcionalidade da edificação e por fim se ocorreram mudanças consideráveis no método construtivo.

\section{FUNDAMENTAÇÃO TEÓRICA}

\section{1 CONCRETO ARMADO}

O concreto armado é composto pelo concreto em si que conforme [5] é uma mistura de água, cimento e agregados, a essa composição é adicionada a armadura de aço formando o concreto armado, é possível moldar essa composição, em qualquer geometria, fazendo-se o uso de fôrmas.

A junção do concreto com aço busca oferecer às estruturas que serão construídas com esse material, resistência à tração e compressão, de acordo com [6] a união do aço e do concreto, nas peças de concreto armado, é o que fornece à estrutura resistência tanto aos esforços de compressão como de tração, pois um material supre a deficiência do outro. Dessa forma o concreto contribuirá para a resistência à compressão e o aço contribuirá para a resistência à tração já que o concreto não trabalha bem à tração.

Assim como nas lajes e vigas, os pilares e as fundações também estão sujeitos a esforços de tração e compressão de acordo com o comportamento estrutural de cada um, é exemplificado por [7] que a carga gerada pelas lajes e vigas gera compressão nos pilares fazendo com que o pilar ceda lateralmente, esse fenômeno é a tração, o que justifica o uso do concreto armado em toda a estrutura e por conta disso é o material mais consumido na construção civil.

O concreto contribui com boa parte do orçamento da obra por conta do volume que deve ser utilizado para compor as estruturas, conforme levantamento realizado por [2] em 2002 e 2003 os gastos com estrutura representam um percentual entre 11,5 a 20,5\%, perdendo apenas para serviços gerais e dentre as estruturas de concreto que compõe uma edificação o pavimento é o elemento que mais consome material.

\section{2 LAJE NERVURADA}

Sabendo que a laje é o elemento que mais contribui para o consumo de concreto e consequentemente para o peso e custo da edificação, tendo em mãos essa informação e analisando o comportamento estrutural das lajes surgiu a ideia da laje nervurada que é uma laje que de acordo com [3] tem a quantidade de concreto, abaixo da linha neutra, reduzida e que por tratar-se da área tracionada é uma área onde o concreto não contribui para combater os esforços de flexão.

De acordo com [7] o concreto resiste bem à compressão e o aço resiste melhor à tração, pois a tensão de ruptura à compressão do concreto é em torno de $15 \mathrm{Mpa}$, já a sua tensão de ruptura à tração é da ordem de 1,5Mpa. Quanto maior o tamanho dos vãos nas edificações, mais as lajes ficarão sujeitas à flexão e por isso o concreto deve compor a parte de cima das lajes, parte esta que sofrerá compressão na flexão e o aço deve compor a parte inferior da laje, parte esta que sofrerá tração na flexão.

É indicado por [8] que há duas formas de classificar a laje nervurada quanto à execução, as moldadas no local (in loco) ou as pré-moldadas. Para efeitos deste artigo foi trabalhado com o tipo de laje nervurada moldada "in loco" normal (direta).

Segundo [3] as lajes nervuradas são compostas por nervuras e uma capa (mesa) que interliga as nervuras conforme 
figura 2. As figuras 1 e 2 mostram as diferenças básicas entre os dois tipos de laje (maciça e nervurada).

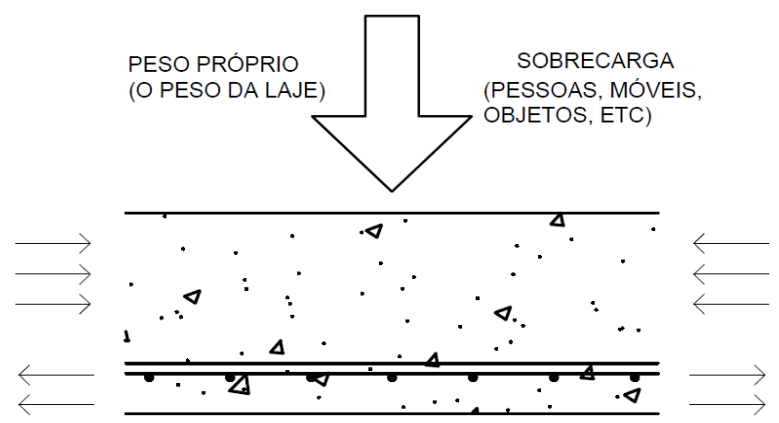

Figura1 - Laje Maciça.

Fonte: Autores, (2019).

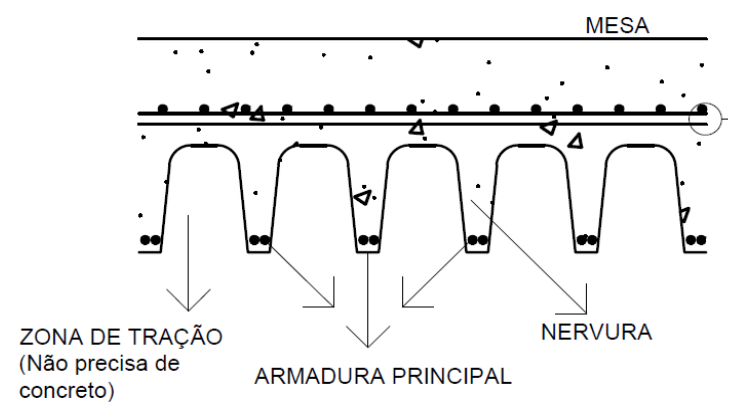

Figura 2 - Laje Nervurada.

Fonte: Autores, (2019).

Além da redução do volume de concreto na parte inferior da laje, a laje nervurada fornece ao projetista a possibilidade de dispensar o uso de vigas para sua sustentação pois conforme [3] as lajes nervuradas moldadas "in loco", laje objeto deste estudo, podem tanto serem apoiadas em paredes de concreto ou alvenaria estrutural como em vigas ou diretamente nos pilares. Caso a estrutura seja sem vigas (apoiada diretamente nos pilares) é necessário combater a punção que será gerada pelo apoio da laje diretamente no pilar.

De acordo com [3] punção pode ser definida como a força que é aplicada em uma pequena área de placa causando a perfuração da mesma, uma situação onde pode ser observado esse fenômeno é no caso de lajes sem vigas onde as lajes são apoiadas diretamente nos pilares, uma força pontual estará reagindo com a laje na área do pilar podendo causar a perfuração da placa.

É indicado por [9] que a punção poderá ser combatida nesses casos utilizando-se de capitel ou viga faixa, capitel é uma região maciça em torno do pilar e vigas faixa são faixas maciças em uma ou duas direções na mesma linha do pilar.

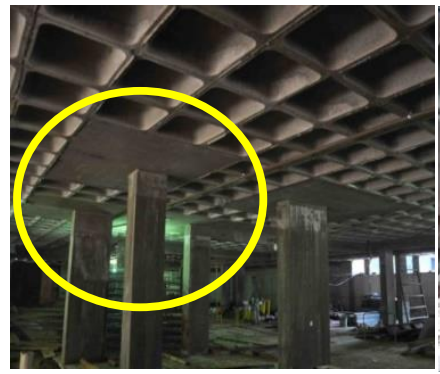

Figura 3 - Capitel. Fonte: [10].

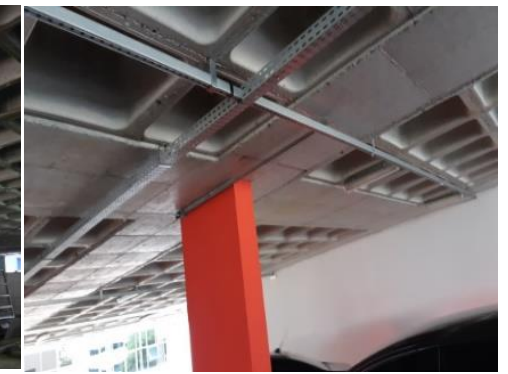

Figura 4 - Viga faixa. Fonte: Autores (2019)
Caso o projetista opte por não utilizar laje nervurada lisa poderá ser utilizada a viga convencional conforme demonstrado na figura 5 .

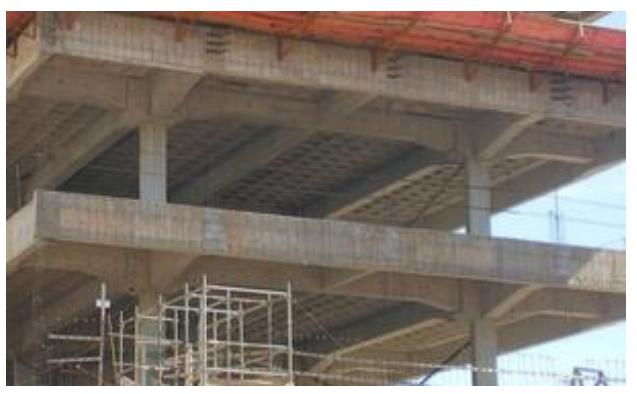

Figura 5 - Viga Convencional. Fonte: [11].

\section{3 CONCRETO ARMADO E CONCRETO PROTENDIDO}

A laje nervurada pode ser armada com armadura ativa ou passiva, [12] explica que a armadura de concreto armado atua de forma passiva tendo em vista que apenas reage à deformação do concreto, já a armadura de protensão atua de forma ativa pois trabalha independente da deformação do concreto.

$\mathrm{O}$ funcionamento do cabo protendido depende do estiramento permanente dos cabos dentro da estrutura de concreto, e conforme [13] ao tentar retornar ao tamanho original o cabo gera uma ação de compressão no concreto impedindo a flexão da estrutura naquele ponto.

É dito por [14] que, como o concreto protendido diminui consideravelmente as chances de elementos fletidos sofrerem flexão a ocorrência de fissuras é quase nula e, caso ocorram, a protensão permite que as mesmas limitem-se a valores insignificantes. Por outro lado o aço do concreto protendido é mais sensível à corrosão que o aço do concreto armado devendo existir alguns cuidados especiais de proteção na fábrica, transporte e obra.

Em se tratando de métodos construtivos para [15] se falarmos em tempo, as estruturas de concreto protendido apresentam maior vantagem em relação às estruturas de concreto armado, pois é possível fazer a desforma de estruturas com armadura ativa em menor tempo devido apresentar maior eficiência no combater à flexão que as estruturas de concreto armado, isso permite redução no cronograma de execução da obra. Porém se falarmos de custos as estruturas de concreto protendido solicitam mão de obra especializada o que encarece esse processo se comparado com o custo da mão de obra de estruturas de concreto armado.

De acordo com [14] o emprego de aço e concreto de alta resistência no concreto protendido permite a essas estruturas maior esbeltez, vãos maiores e menor peso próprio quando comparadas às estruturas de concreto armado e essa característica aumenta a flexibilidade no que se refere aos tamanhos dos vãos o que gera uma redução no número de pilares e a isto está atrelado a utilização de menos material se comparado com as estruturas de concreto armado.

Protender a armadura traz mais risco com relação à corrosão, como já mencionado, por isso conforme explanado por [16] o concreto utilizado na protensão exige maior controle nos processos de fabricação, lançamento e vibração, assim como também deve ser garantido o cobrimento mínimo da armadura, e por requerer controles rigorosos e maior qualidade na execução é necessário o emprego de mão-de-obra especializada. Por isso a estrutura de concreto armado leva vantagem apenas com relação à mão-de-obra para execução pois não precisa de mão de obra especializada como a estrutura de concreto protendido. 
Conforme [17] o concreto protendido é geralmente empregado em edifícios garagem de vários pavimentos, pois a razão vão/altura exigida pela estrutura de concreto armado não permite aos projetistas atingirem grandes vãos. Portanto dependendo do tipo de edificação e a funcionalidade a que esta se destina as vantagens de utilização de estruturas de concreto protendido ou armado variam.

Para edificações de pequeno porte por exemplo, talvez seja mais vantajoso a utilização de laje maciça de concreto armado já que não necessita de mão de obra e material especializados e de acordo com [3] a solução com laje nervurada permite uma redução no uso do concreto porém com um pequeno aumento de consumo de aço e só se torna economicamente viável a partir do aumento do vão ou se apresentar uma relação entre os lados maior que dois.

\section{RESULTADOS E DISCURSÕES \\ III. 1 CARACTERÍSTICAS DA EDIFICAÇÃO}

$\checkmark$ Edifício Garagem com 5 pavimentos mais térreo;

$\checkmark$ Área construída: 8.374,2 $\mathrm{m}^{2}$

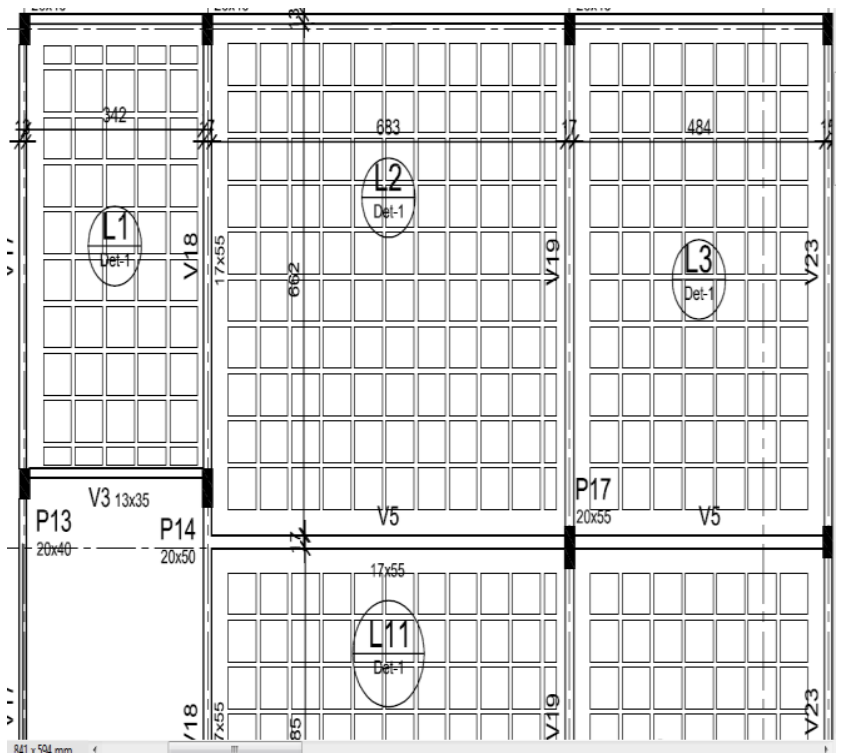

Figura 6 - Detalhe da laje nervurada de concreto armado. Fonte: [18].

Pelo detalhe da laje apresentado na figura 6 acima verifica-se que o engenheiro considerou para a laje nervurada de concreto armado, do projeto objeto de estudo deste artigo, vigas convencionais.

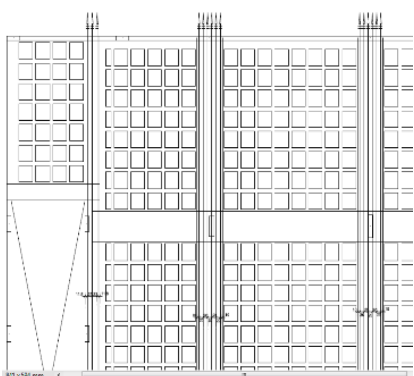

Figura 7 - Laje nervurada Protendida (distribuição vertical dos cabos).

Fonte: [19].

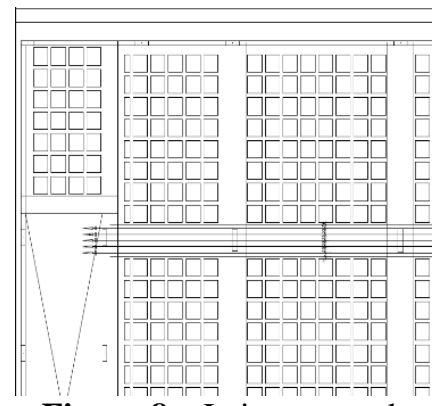

Figura 8 - Laje nervurada Protendida (distribuição horizontal dos cabos).

Fonte: [20].
Pelas imagens da laje nervurada de concreto protendido, na figura 7 acima, retiradas do projeto objeto de estudo deste artigo, verificou-se que o engenheiro optou por utilizar viga faixa nas duas direções (horizontal e vertical), verifica-se ainda que os cabos de protensão foram dispostos nas vigas faixa e que as mesmas ocupam um volume representativo da laje.

\section{2 QUANTIDADE DE MATERIAL UTILIZADO}

Este trabalho limitar-se-á a analisar quanto material foi consumido pela infraestrutura e superestrutura de cada tipo de laje.

Os dados apresentados nos gráficos 1 e 2 abaixo foram retirados dos resumos disponibilizados nos projetos estruturais da laje nervurada de concreto armado e protendido.

\section{Quantidade de Materiais Utilizados na Infraestrutura}

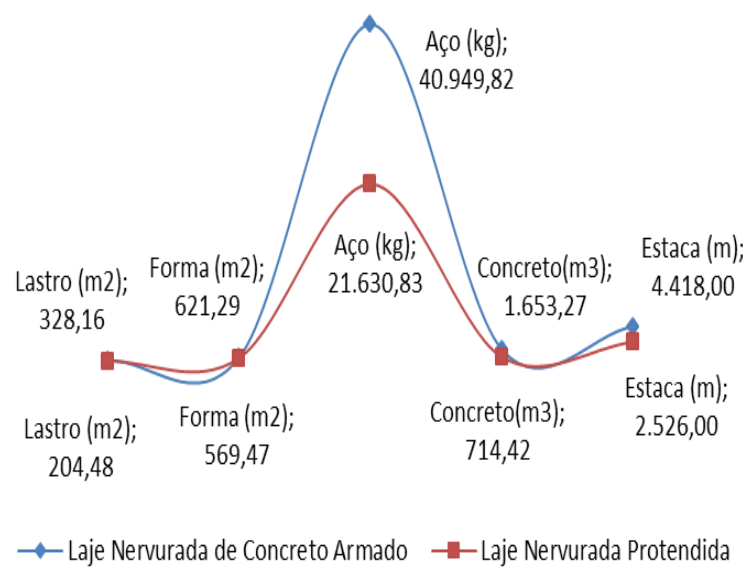

Gráfico 1 - Comparativo infraestrutura. Fonte: Autores (2019).

Quantidade de Materiais Utilizados na Superestrutura

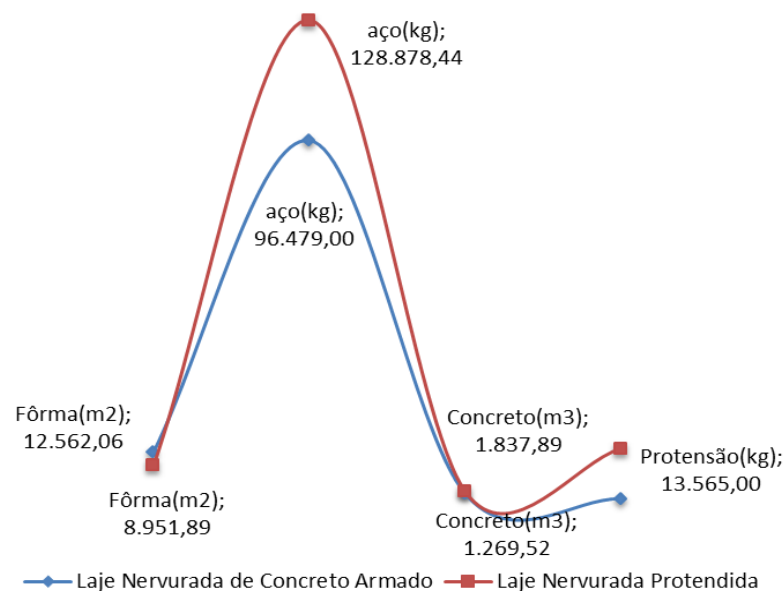

Gráfico 2 - Comparativo Superestrutura.

Fonte: Autores (2019).

Da análise dos gráficos pode ser verificado que dos itens que compõem a infraestrutura (aço, concreto, forma, lastro de concreto e estacas) a laje nervurada protendida utilizou menos material em todos os itens, em armadura de aço, concreto e estacas a diferença foi em torno de $50 \%$ para cada item.

Já para os itens que compõem a superestrutura (aço, concreto, forma e protensão) a laje nervurada protendida utilizou 
menos material em forma apenas, uma redução em torno de $30 \%$ quando comparado à laje de concreto armado.

Armadura de aço teve um acréscimo de $25 \%$ e concreto um acréscimo de $30 \%$ em relação a estrutura de concreto armado.

Observa-se que a estrutura de concreto protendido para este projeto especificamente utilizou mais concreto e aço que a estrutura de concreto armado na superestrutura e esse aumento deuse principalmente por conta da utilização de vigas faixas nas duas direções (horizontal e vertical) o que consumiu uma quantidade alta de material pelo fato das vigas faixas ocuparem um volume considerável da laje.

Porém na infraestrutura a estrutura de concreto protendido utilizou a metade dos materiais utilizados na estrutura de concreto armado e isso deve-se à redução da quantidade de pilares obtida com a implantação da protensão o que consequentemente diminuiu a quantidade de blocos e estacas de fundação.

\section{3 TABELA COMPARATIVA DE ITENS ESTRUTURAIS}

Os dados apresentados na tabela 1 abaixo foram retirados dos resumos disponibilizados nos projetos estruturais.

As vigas faixas não foram contabilizadas como vigas para elaboração da tabela já que as mesmas são embutidas na laje.

A quantidade de vigas que consta na tabela para a laje nervurada de concreto protendido diz respeito às vigas de borda.

É possível observar da análise da tabela que o número de elementos estruturais reduziu consideravelmente quando adicionada a protensão.

Para a laje nervurada de concreto armado foi possível utilizar vãos de até 7,00m. Já para a laje nervurada protendida foram utilizados vãos de até $10,0 \mathrm{~m}$.
Fazendo uma análise da funcionalidade da edificação, por tratar-se de um edifício garagem, sua função principal é possibilitar o estacionamento do maior número de veículos e para viabilizar essa demanda o projeto deve prevê o menor número de pilares possível.

Com isso observando-se a tabela verifica-se que o projeto de laje protendida apresentou menor número de pilares possibilitando vãos maiores em relação à laje de concreto armado.

\section{4 DIMENSÃO DOS PILARES}

Conforme pode ser observado no levantamento organizado na tabela 2 abaixo, para a laje de concreto Armado a área de pilares ficou entre $0,060 \mathrm{~m}^{2}$ e $0,110 \mathrm{~m}^{2}$.

Já para a laje de Concreto Protendido a área de pilares ficou entre $0,076 \mathrm{~m}^{2}$ e $0,225 \mathrm{~m}^{2}$, demonstrando que os pilares da laje de concreto protendido, apesar de serem menos, possuem maior volume.

Tabela 2 - Dimensão dos Pilares.

\begin{tabular}{|c|c|c|c|c|c|}
\hline \multicolumn{4}{|c|}{ Laje de Concreto Armado } & \multicolumn{4}{|c|}{ Laje de Concreto Protendido } \\
\hline $\begin{array}{c}\text { Dimensão } \\
(\mathrm{cm})\end{array}$ & Qtd & Área $\left(\mathrm{m}^{2}\right)$ & Dimensão $(\mathrm{cm})$ & Qtd & $\begin{array}{c}\text { Área } \\
\left(\mathrm{m}^{2}\right)\end{array}$ \\
\hline $20 \times 40$ & 48 & 0,080 & $60 \times 19$ & 31 & 0,110 \\
\hline $17 \times 40$ & 10 & 0,068 & $60 \times 20$ & 03 & 0,120 \\
\hline $20 \times 50$ & 07 & 0,100 & $80 \times 25$ & 04 & 0,200 \\
\hline $20 \times 55$ & 04 & 0,110 & $90 \times 25$ & 04 & 0,225 \\
\hline $17 \times 60$ & 02 & 0,102 & $60 \times 25$ & 03 & 0,150 \\
\hline $15 \times 40$ & 02 & 0,060 & $40 \times 19$ & 02 & 0,076 \\
\hline
\end{tabular}

Fonte: Autores, (2019).

\section{5 COMPARATIVO DE ORÇAMENTOS}

Tabela 3 - Tabela comparativa de Orçamentos.

\begin{tabular}{|c|c|c|c|c|}
\hline INFRAESTRUTURA & $\mathbf{U}$ & QTDD & $\begin{array}{l}\text { Valor } \\
\text { Unit. } \\
\text { R\$ }\end{array}$ & $\begin{array}{c}\text { Valor Total } \\
\mathbf{R} \$\end{array}$ \\
\hline $\begin{array}{c}\text { Lastro Concreto Magro c/ Seixo e }= \\
5 \mathrm{~cm} \text { Preparo e Lançamento }\end{array}$ & $\mathrm{m}^{2}$ & 328,16 & 19,77 & $6.487,72$ \\
\hline $\begin{array}{l}\text { Forma Tábuas p/ Fundação, Fabric. } \\
\text { Mont. Desforma Aproveit. } 2 \text { Vezes }\end{array}$ & $\mathrm{m}^{2}$ & 621,29 & 32,69 & $20.309,97$ \\
\hline $\begin{array}{l}\text { Estacas Hélice Contínua d=310mm } \\
\text { até } 35 \mathrm{TF},(\text { Perfuração) } \mathrm{s} / \text { materiais }\end{array}$ & $\mathrm{m}$ & $1.580,00$ & 46,53 & $73.517,40$ \\
\hline $\begin{array}{l}\text { Estacas Hélice Contínua d=350mm } \\
\text { até 50TF,(Perfuração) s/materiais }\end{array}$ & $\mathrm{m}$ & $2.838,00$ & 53,80 & $152.684,40$ \\
\hline $\begin{array}{c}\text { Concreto Estrutural Fck }=30 \text { mpa em } \\
\text { Fundaçao (Preparo, Lançamento e } \\
\text { Aplicaçao) }\end{array}$ & $\mathrm{m}^{3}$ & $1.653,27$ & 587,63 & $971.511,05$ \\
\hline $\begin{array}{c}\text { Armadura aço Para Estruturas em } \\
\text { Geral, CA-50 Todas Bitolas, Corte e } \\
\text { Dobra Industrial Fora da Obra } \\
\end{array}$ & $\mathrm{kg}$ & $40.949,82$ & 5,45 & $223.176,52$ \\
\hline TOTAL & & & & $1.447 .687,06$ \\
\hline SUPERESTRUTURA & $\mathbf{U}$ & QTDD & $\begin{array}{l}\text { Valor } \\
\text { Unit. } \\
\text { R\$ }\end{array}$ & $\begin{array}{l}\text { Valor Total } \\
\mathbf{R} \$\end{array}$ \\
\hline $\begin{array}{l}\text { Montagem/desmontagem de fôrma } \\
\text { de pilares retangulares e estruturas } \\
\text { similares com área média das } \\
\text { seções }>0,25 \mathrm{~m}^{2} \text {, pé-direito simples, } \\
\text { em chapa de madeira compensada } \\
\text { resinada, } 2 \text { utilizações. af_12/2015 }\end{array}$ & $\mathrm{m}^{2}$ & $1.619,90$ & 80,20 & $129.915,98$ \\
\hline $\begin{array}{c}\text { Montagem/desmontagem fôrma de } \\
\text { viga, escoramento metálico, pé- } \\
\text { direito simples, em chapa de } \\
\text { madeira resinada, } 2 \text { utilizações. } \\
\text { af_12/2015 }\end{array}$ & $\mathrm{m}^{2}$ & $4.429,46$ & 91,24 & $404.143,93$ \\
\hline $\begin{array}{c}\text { Forma para laje nervurada com } \\
\text { cimbramento e escoramento } \\
\text { metálico (plasterit+cubetas } \\
\text { +vigas+cubetas+acessórios) }\end{array}$ & $\mathrm{m}^{2}$ & $6.513,60$ & 82,71 & $538.739,86$ \\
\hline $\begin{array}{c}\text { Armadura aço Para Estruturas em } \\
\text { Geral, CA-50 Todas Bitolas, Corte e } \\
\text { Dobra Industrial Fora da Obra }\end{array}$ & $\mathrm{kg}$ & $96.479,00$ & 5,45 & $525.810,55$ \\
\hline $\begin{array}{c}\text { Concreto Estrutural Fck }=30 \mathrm{mpa} \text { em } \\
\text { Estrutura (Preparo, Lançamento e } \\
\text { Aplicaçao) }\end{array}$ & $\mathrm{m}^{3}$ & $1.269,52$ & 587,63 & $746.008,04$ \\
\hline TOTAL & & & & $2.344 .618,35$ \\
\hline
\end{tabular}

\begin{tabular}{|c|c|c|c|}
\hline INFRAESTRUTURA & QTDD & $\begin{array}{l}\text { Valor } \\
\text { Unit. } \\
\text { R\$ }\end{array}$ & $\begin{array}{c}\text { Valor Total } \\
\mathbf{R} \$\end{array}$ \\
\hline $\begin{array}{l}\text { Lastro Concreto Magro c/ Seixo e }=5 \\
\mathrm{~cm} \text { Preparo e Lançamento }\end{array}$ & 204,48 & 19,77 & $4.042,53$ \\
\hline $\begin{array}{l}\text { Forma Tábuas p/ Fundação, Fabric. } \\
\text { Mont. Desforma Aproveit. } 2 \text { Vezes }\end{array}$ & 569,47 & 32,69 & $18.616,08$ \\
\hline $\begin{array}{l}\text { Estacas Hélice Contínua d=410mm } \\
\text { até 60TF,(Perfuração } \mathrm{s} / \text { materiais }\end{array}$ & 865,80 & 36,39 & $31.506,46$ \\
\hline $\begin{array}{l}\text { Estacas Hélice Contínua } \mathrm{d}=500 \mathrm{~mm} \\
\text { até } 60 T \mathrm{~T},(\text { Perfuração) } \mathrm{s} / \text { materiais }\end{array}$ & $1.660,97$ & 59,15 & $98.246,38$ \\
\hline $\begin{array}{l}\text { Concreto Estrutural Fck=20 mpa em } \\
\text { Estrutura (Preparo, Lançamento e } \\
\text { Aplicaçao) } 400 \mathrm{~kg} \text { de cimento }\end{array}$ & 575,96 & 547,40 & $315.277,99$ \\
\hline $\begin{array}{c}\text { Concreto Estrutural Fck }=30 \text { mpa em } \\
\text { Estrutura (Preparo, Lançamento e } \\
\text { Aplicaçao) }\end{array}$ & 138,46 & 587,63 & $81.362,71$ \\
\hline $\begin{array}{l}\text { Armadura aço Para Estruturas em } \\
\text { Geral, CA-50 Todas Bitolas, Corte e } \\
\text { Dobra Industrial Fora da Obra }\end{array}$ & $21.630,83$ & 5,45 & $117.888,05$ \\
\hline TOTAL & & & $666.940,19$ \\
\hline SUPERESTRUTURA & QTDD & $\begin{array}{l}\text { Valor } \\
\text { Unit. } \\
\text { R\$ }\end{array}$ & $\begin{array}{c}\text { Valor Total } \\
\mathbf{R} \$\end{array}$ \\
\hline $\begin{array}{l}\text { Montagem/desmontagem de fôrma } \\
\text { de pilares retangulares e estruturas } \\
\text { similares com área média das } \\
\text { seções }>0,25 \mathrm{~m}^{2} \text {, pé-direito simples, } \\
\text { em chapa de madeira compensada } \\
\text { resinada, } 2 \text { utilizações. af_12/2015 }\end{array}$ & $1.183,00$ & 80,20 & $94.876,41$ \\
\hline $\begin{array}{c}\text { Montagem e desmontagem de fôrma } \\
\text { de viga, escoramento metálico, pé- } \\
\text { direito simples, em chapa de } \\
\text { madeira resinada, } 2 \text { utilizações. } \\
\text { af_12/2015 }\end{array}$ & $1.717,88$ & 91,24 & $156.739,35$ \\
\hline $\begin{array}{l}\text { Forma para laje nervurada com } \\
\text { cimbramento e escoramento } \\
\text { metálico (plasterit+cubetas } \\
\text { +vigas+cubetas+acessórios) }\end{array}$ & $6.267,80$ & 82,71 & $518.409,90$ \\
\hline $\begin{array}{l}\text { Armadura aco Para Estruturas em } \\
\text { Geral, CA-50 Todas Bitolas, Corte e } \\
\text { Dobra Industrial Fora da Obra }\end{array}$ & $128.878,44$ & 5,45 & $702.387,48$ \\
\hline $\begin{array}{c}\text { Concreto Estrutural Fck }=30 \text { mpa em } \\
\text { Estrutura (Preparo, Lançamento e } \\
\text { Aplicaçao) }\end{array}$ & $1.837,89$ & 587,63 & $1.080 .002,16$ \\
\hline Protensão & $13.565,00$ & 15,90 & $215.683,50$ \\
\hline TOTAL & & & $2.768 .098,81$ \\
\hline
\end{tabular}

Fonte: Autores, (2019). 
Tabela 1 - Tabela comparativa de itens estruturais.

\begin{tabular}{|l|c|c|c|c|c|}
\hline $\begin{array}{c}\text { Laje } \\
\text { Nervurada }\end{array}$ & Viga & Pilar & Laje & Bloco & Estaca \\
\hline $\begin{array}{l}\text { Concreto } \\
\text { Armado }\end{array}$ & 214 & 74 & 44 & 74 & 208 \\
\hline $\begin{array}{l}\text { Concreto } \\
\text { Protendido }\end{array}$ & 23 & 47 & 23 & 47 & 122 \\
\hline
\end{tabular}

Fonte: Autores, (2019).

Os orçamentos sintéticos aqui apresentados, conforme tabela 3, foram elaborados utilizando-se os dados de quantitativos obtidos através dos projetos estruturais dos dois tipos de laje e para a valoração dos itens foram utilizados como base os dados de [21], [22] e [23].

Da análise dos orçamentos apresentados pode ser verificado que os custos com infraestrutura foram consideravelmente reduzidos quando adicionada a protensão o que representou uma economia de $\mathrm{R} \$ 780.746,87$. O gasto com infraestrutura na laje protendida foi $54 \%$ inferior aos gastos com infraestrutura na laje de concreto armado.

Já os custos com a superestrutura aumentaram em $\mathrm{R} \$ 423.480,46$ a partir da utilização da protensão, parte desse aumento deve-se à adição da protensão à laje que representa sozinho um acréscimo de $\mathrm{R} \$ 215.683,50$. O gasto com superestrutura na laje protendida foi $15,3 \%$ superior ao gasto com superestrutura na laje de concreto armado.

Apesar da superestrutura ter apresentado acréscimo no orçamento com a adição da protensão, a diferença total dos orçamentos, somando a infraestrutura e a superestrutura, entre a laje nervurada de concreto armado e a laje nervurada de concreto protendido é de $\mathrm{R} \$ 357.266,42$, valor este que representa uma redução de $9,4 \%$ no projeto da laje de concreto protendido quando comparamos com o valor total da estrutura de concreto armado.

\section{CONCLUSÃO}

Espera-se de uma estrutura de concreto protendido que o consumo de material seja reduzido na superestrutura o que neste caso aconteceu na infraestrutura, porém essa redução de custos com infraestrutura está inteiramente relacionada com a implantação de concreto protendido o que permitiu aumentar os vãos e reduzir consideravelmente o número de pilares.

A consequência lógica da redução do número de pilares é a redução do número de itens de fundação já que os pilares transmitem as cargas diretamente às fundações, para tanto o projetista utilizou, no projeto de laje nervurada de concreto protendido, estacas de diâmetros maiores com maior capacidade de absorção de força se compararmos às estacas utilizadas no projeto da laje nervurada de concreto armado, conforme pode ser observado na tabela 3. Com isso o projeto de concreto protendido demonstrou-se mais vantajoso economicamente.

Por tratar-se de edifício garagem a laje de concreto protendido também apresentou mais ganhos pela viabilidade de utilizar-se vãos maiores de até $10 \mathrm{~m}$ contra $7 \mathrm{~m}$ apresentados no projeto da laje nervurada de concreto armado.

A laje de concreto protendido apresentou-se mais atraente também quanto ao método construtivo pois permite a desforma em menor tempo, já no aspecto de mão-de-obra a laje de concreto armado ganha por não precisar de mão-de-obra especializada.

Apesar de a armadura de protensão apresentar maior risco de corrosão as armaduras protendidas disponíveis no mercado fornecem materiais de qualidade suficiente que garantem a segurança quanto a este risco se observadas todas as medidas de segurança contra corrosão orientadas.
Dessa forma, para este estudo de caso, a comparação entre a utilização de concreto armado e concreto protendido em laje nervurada para a construção de um edifício garagem nos levou a concluir que a utilização da laje nervurada de concreto protendido atendeu melhor aos requisitos de custo, qualidade e funcionalidade desejados.

\section{REFERÊNCIAS}

[1] Bauer, Luiz Alfredo Falcão. Materiais de Construção I. 5. ed. rev. Rio de Janeiro: LTC, 2000. 1 v.

[2] Goldman, Pedrinho. Introdução ao planejamento e controle de custos na construção civil brasileira. 4. ed. São Paulo: PINI, 2004. $176 \mathrm{p}$.

[3] Carvalho, Roberto Chust; Pinheiro, Líbano Miranda. Cálculo e detalhamento de estruturas usuais de concreto armado. São Paulo: PINI, 2009. 2 v.

[4] Associação Brasileira de Normas Técnicas. NBR 6118: Projeto de estruturas de Concreto: Procedimento. Rio de Janeiro,2014.

[5] Adão, Francisco Xavier; Hemerly, Adriano Chequetto. Concreto Armado: Novo Milênio: cálculo prático e económico. 2. ed. rev. e atual. Rio de Janeiro: Interciência, 2010.

[6] Borges, Alberto Nogueira. Curso Prático de Cálculo em Concreto Armado: Projetos de Edifícios. 2. ed. Rio de Janeiro: Imperial Novo Milênio, 2010. 251 p.

[7] Botelho, Manoel Henrique Campos; MARCHETTI, Osvaldemar. Concreto Armado Eu Te Amo. 8. ed. rev. São Paulo: Edgard Blucher Ltda, 2015. 1 v.

[8] Porto, Thiago Bomjardim; FERNANDES, Danielle Stefane Gualberto. Curso Básico de Concreto Armado. São Paulo: Oficina de Textos, 2015. 208 p.

[9] Pinheiro, Líbano Miranda. Fundamentos do Concreto e Projetos de Edifícios. Notas de aula. Universidade de São Paulo, São Carlos, 2007.

[10] Pretto, Sloane. Fôrmas Plásticas para Laje Nervurada. 2013. Disponível em: https://www.ufrgs.br/eso/content/?tag=lajenervurada>. Acesso em: 18 de fev. 2019.

[11] AECweb. Laje Nervurada Alivia Peso de Estruturas de 148m de extensão. 2009.Disponível em:

$<$ https://www.aecweb.com.br/emp/cont/m/laje-nervurada-aliviapeso-de-estruturas-de-148m-de-extensao_3453_2350>. Acesso em: 18 de fev. 2019.

[12] Carvalho, Roberto Chust. Estrutura em Concreto Protendido: Cálculo e detalhamento. São Paulo: PINI, 2012. 1 v.

[13] Bastos, Paulo Sérgio. Concreto Protendido. Notas de aula. Universidade Estadual Paulista, Bauru, 2019.

[14] Leonhardt, Fritz. Construções de Concreto: Concreto Protendido. Rio de Janeiro: Interciência, 1983. 5 v.

[15] Emerick, Alexandre Anozé. Projeto e Execução de Lajes Protendidas. 1. ed. Rio de Janeiro: Interciência, 2005. 192 p. 
[16] Yazigi, Walid. A Técnica de Edificar. 11 ed. rev. e atual. São Paulo: PINI, 2011. 807 p.

[17] Garrison, Philip. Fundamentos de Estruturas. 3. Ed. São Paulo: Bookman, 2018. 428 p.

[18] Brito, Marcílio. Edifício Garagem - Forma do 1 ao 5 piso. 2014. Etapa: Projeto Estrutural, prancha 003.

[19] Anastácio, Francisco. Elevação dos cabos verticais das Lajes do 1 ao 4 pav. 2015. Obra: Edifício Garagem, prancha 025.

[20] Anastácio, Francisco. Fretagem dos cabos Horizontais das Lajes do 1 ao 4 pav. 2015. Obra: Edifício Garagem, prancha 026.

[21] Secretaria de Estado de Infraestrutura. Tabela Sintética com desoneração: Custo Referencial de Serviços. Manaus, AM, 2014. $49 \mathrm{p}$.

[22] Secretaria de Estado de Infraestrutura. Tabela Sintética com desoneração: Custo Referencial de Serviços. Manaus, AM, 2015. $49 \mathrm{p}$.

[23] SBA Engenharia. Composição própria de custos. Manaus, AM, 2016. 